\title{
STUDY OF IMPACT OF SOME CHANGES ON GROUNDWATER SYSTEM IN NILE DELTA AQUIFER
}

Ismail M. Abd-elaty, Hany F. Abd-elhamid, Maha R.Fahmy, Gamal M. Abd- elaal

\begin{abstract}
The climatic changes are considered one of the most important natural phenomena as a dangerous challer human beings. The main objectives of this research are study the impact of climatic changes on water rec delta aquifer, using VISUAL MUDFLOW to simulate the effect of increase in SLR due to expected increase ir temperature, decrease in surface water system due to decrease in surface water level of the Nile or constr structures such as Grand Renaissance Dam, Ethiopia increasing abstraction rates due to increase in popula and combinations of these scenarios. The model was calibrated under current conditions based on availabl 2008 which is considered as a base case. Four different scenarios are considered. The first scenario increa: by 25, 50 and $100 \mathrm{~cm}$, the second scenario decreases surface water by 25, 50 and $100 \mathrm{~cm}$, the third scer increases wells extraction rate by 25,50 and $100 \%$, and the fourth scenario is a combination of three sce result shows that increasing SLR leads to increase in groundwater level (GWL) in the North and decrease it It is also observed that decreasing surface water, increasing extraction rate from wells and combination of scenarios leads to a decrease in GWL. Finally, increasing SLR, decreasing surface water and increasing ext have significant effect on groundwater level but combination of these scenarios will have very dangerous $e$ resources in Nile delta aquifer
\end{abstract}

